\title{
Novel modalities for the diagnosis of cardiac surgery associated acute kidney injury: a narrative review of the literature
}

\author{
G Pettey, P Motshabi
}

\section{Department of Anaesthesiology, Charlotte Maxeke Johannesburg Academic Hospital, University of the Witwatersrand, South Africa Corresponding author, email: gabi.pettey@gmail.com}

Acute kidney injury (AKI) is a common complication post cardiac surgery and increases mortality during hospitalisation fivefold. If present, it is an independent risk factor for progression to chronic kidney disease. When renal replacement therapy (RRT) is required, it carries a $50 \%$ mortality rate for cardiac surgery associated (CSA) AKI. Given the dynamic nature of CSA AKI, it is imperative to implement preventative and management strategies to: prevent or limit ischaemia; reduce systemic inflammation; modify amenable pre- and perioperative risk factors; and address nutritional and fluid status at the pre- intra- and postoperative stages. Conventional modalities in the diagnosis of AKI have proven ineffectual in the timely diagnosis, and rely mostly on nonspecific biometric parameters, namely a rise in serum creatinine, and a decrease in urine output. Novel biomarkers have promoted new ideas in the search for more effective, precise and reproducible tools to aid diagnosis. In addition, ultrasonic tools for renal, hepatic and portal vascular flow patterns using Duplex Doppler for venous flow parameters, together with renal arterial resistive index, have been used as novel predictors of perioperative AKI. Although these parameters require further investigation, Duplex Doppler of the renal, hepatic, portal and cardiac systems appear to have promising results in the early detection of AKI.

Keywords: acute kidney injury, cardiac surgery, renal ultrasound, portal ultrasound, hepatic ultrasound, Duplex Doppler, NGAL, TIMP-2, IGFBP7, venous congestion, venous flow patterns, resistive index (RI), intrarenal venous flow patterns, portal pulsatility, NephroCheck ${ }^{\circledast}$

\section{Introduction}

The aetiology of AKI is multifactorial; however, patients undergoing cardiac surgery are said to have a $40 \%$ probability of developing AKI. ${ }^{1}$ It is a pervasive disease, whose diagnosis evades practitioners until significant functional reserve has been lost. The current diagnostic modalities are not time-sensitive in detecting potentially irreversible injury.1-12 Given the magnitude of this condition, as well as the considerable complications that can occur, such as the requirement of renal replacement therapy (RRT), long-term renal dysfunction or chronic renal disease and mortality, it is imperative to establish preventative measures and early diagnosis. ${ }^{2,3,13-15}$ Current common practice makes use of

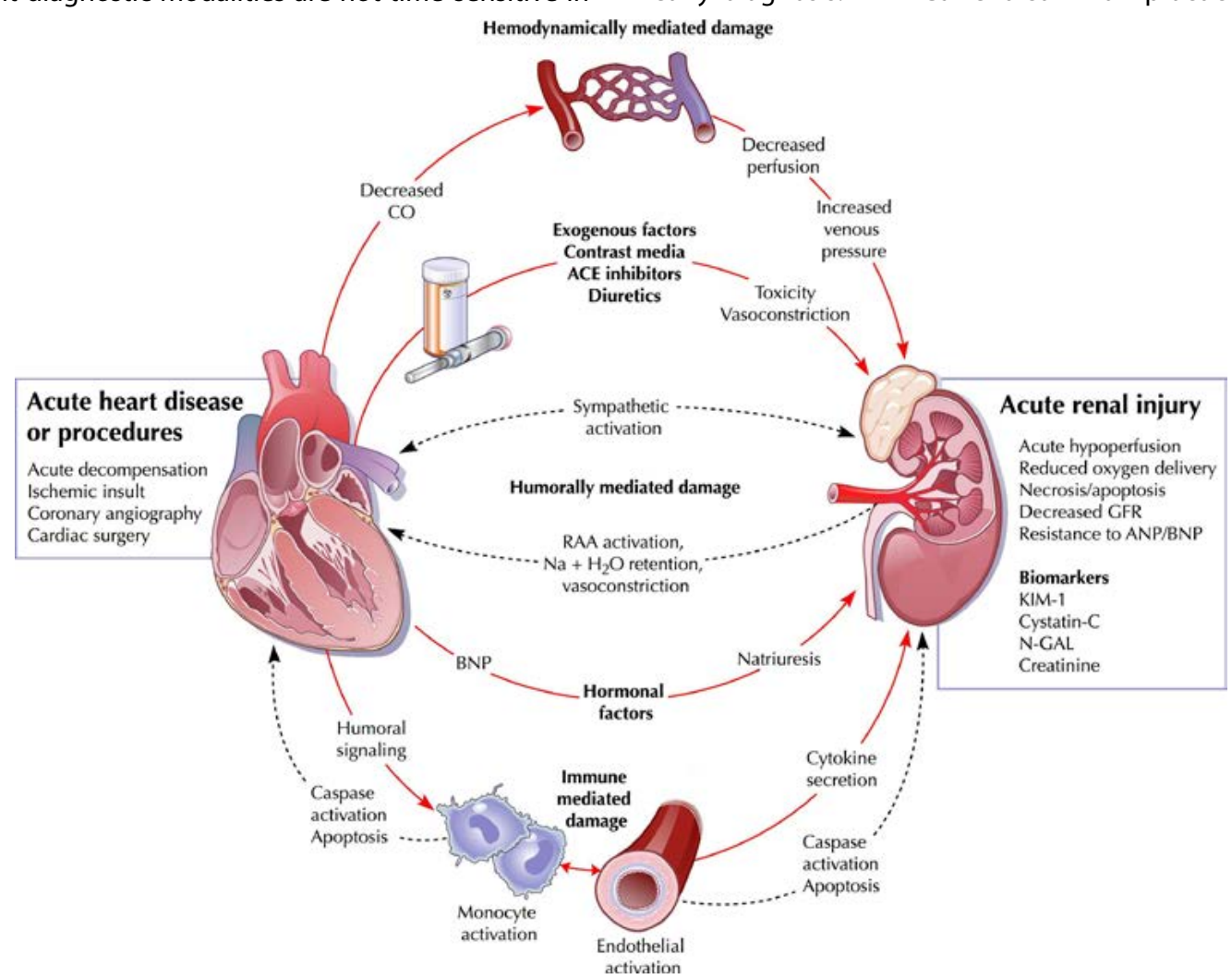

Figure 1: Pathophysiological interactions of Acute Cardiorenal Syndrome ${ }^{60}$ 
the Kidney Development Improving Global Outcomes (KDIGO) group classification system for diagnosis of AKI, however, these parameters have proven ineffectual for timely diagnosis. New modalities are constantly being investigated, including conventional testing, urinary and blood biomarkers, as well as the use of ultrasound. ${ }^{1-3,5,13,16-18}$

\section{Physiology of AKI}

AKI is a well-recognised complication post cardiac surgery, 1,3,13,14 which progresses to kidney dysfunction requiring RRT in 2-5\% of patients, ${ }^{15}$ chronic kidney disease (CKD) and mortality, if not treated timeously and judiciously. 1,3,13,16,19 Although AKI is multifactorial in origin, its aetiology post cardiac surgery is compounded by unique considerations.

The physiological profile of many patients presenting for cardiac surgery includes multiple comorbidities, such as hypertension, diabetes, hypercholesterolaemia, chronic illness (cardiac, hepatic, renal, peripheral vascular) and advanced age, all of which increase the likelihood of CSA AKI occurring (Figure 1). 3,5,16

Surgical factors also pose additional risk: the nature of the surgery (valvular, CABG, congenital deformity), complexity of the surgery, use and duration of cardiopulmonary bypass (CPB), CPB perfusion pressure, use of blood products, haemodynamic instability, ischaemia-reperfusion injury, aortic cross-clamping, intraoperative thrombo-embolic phenomena, arrhythmias, and myocardial infarction. All these increase the probability of CSA AKI occurring perioperatively. ${ }^{1,5,13,16,19-21}$

The pathophysiology of CSA AKI is presumed to originate predominantly intraoperatively, mostly due to acute tubular necrosis. $2,3,5,22,23$ Some of the factors at play are CPB-associated systemic inflammatory response, CPB pump pressure, damage to the endothelial glycocalyx, hypovolaemia and hypoperfusion, haemolysis, oxidative damage, sympathetic nervous system activation and the use of nephrotoxic agents (angiotensin converting enzyme inhibitors, contrast dyes). 1,2,4,5,16,20,21

Whilst kidney arterial perfusion parameters have previously enjoyed attention with regards to intra- and postoperative anticipation and prediction of the onset of $A K I, 1,5,13,15,16,24-28$ recent focus has turned to the venous system, particularly looking at venous congestion of the renal, portal and hepatic systems as possible predictors of AKI. ${ }^{26,29-38}$

\section{Conventional biomarkers of AKI}

Serum creatinine $(\mathrm{SCr})$ levels and urine production are the conventional biometric parameters used to stage AKI, but these are non-specific, delayed-response parameters that result in late diagnosis.,3,22 These parameters have been used extensively in defining criteria, scores and classifications in the diagnoses of AKI. Previously, AKI was defined using the Risk/Injury/Failure/ Loss/End-stage (RIFLE) criteria, which categorises the exposure (risk/injury/failure), and the outcome (loss/end-stage). ${ }^{39}$

The Acute Kidney Injury Network (AKIN) criteria, was developed to follow the RIFLE criteria, which modified certain aspects of
Table I: KDIGO staging classification system $\mathrm{AKI}^{3}$

\begin{tabular}{|c|c|c|}
\hline Stage & Serum creatinine & Urine output \\
\hline 1 & $\begin{array}{l}1.5-1.9 \text { times baseline } \\
\text { OR } \\
\geq 0.3 \mathrm{mg} / \mathrm{dl}(\geq 26.5 \mu \mathrm{mol} / \mathrm{l}) \text { increase }\end{array}$ & $\begin{array}{l}<0.5 \mathrm{ml} / \mathrm{kg} / \mathrm{h} \text { for } \\
6-12 \text { hours }\end{array}$ \\
\hline 2 & 2.0-2.9 times baseline & $\begin{array}{l}<0.5 \mathrm{ml} / \mathrm{kgh} \text { for } \\
\geq 12 \text { hours }\end{array}$ \\
\hline 3 & $\begin{array}{l}3.0 \text { times baseline } \\
\text { OR } \\
\text { Increase in serum creatinine to } \\
>4.0 \mathrm{mg} / \mathrm{dl}(\geq 353.6 \mu \mathrm{mol} / \mathrm{l}) \\
\text { OR Initiation of renal replacement } \\
\text { therapy } \\
\text { OR } \\
\text { In patients }<18 \text { years, decrease in } \\
\text { eGFR to }<35 \mathrm{ml} / \mathrm{min} \text { per } 1.73 \mathrm{~m}^{2}\end{array}$ & \\
\hline
\end{tabular}

the RIFLE criteria, notably additions were to: the time period which was shortened from seven days to 48 hours; the initiation of RRT regardless of SCr levels; the removal of glomerular filtration rate from the classification system; lower $\mathrm{SCr}$ level threshold for diagnosis of AKI; and removal of the assumption of normal SCr levels in the absence of this information. ${ }^{39}$ In a retrospective analysis conducted by Bastin et al. ${ }^{39}$ it was noted that AKI diagnosis using the AKIN criteria was associated with a significantly increased incidence of hospital mortality when compared to the RIFLE criteria ( 0.86 vs $0.78, p=0.0009$ ).

Currently, the most widely used criteria for AKI is that proposed by the KDIGO group ${ }^{3}$ (Table I).

Central to the contemporary management of AKI is early detection and institution of preventative measures. Preventative strategies, such as appropriate use of fluids including avoidance of positive fluid balance and renal venous congestion, nutritional optimisation, avoidance of nephrotoxic agents, limiting CPB exposure, and use of experimental agents (calcium channel blockers, dexmedetomidine, high-dose steroids, fenoldopam) have been described.1,3,13-19 However, the current diagnostic criteria fail to assist in providing a timely diagnosis for some of these measures to be effective. ${ }^{1,3,4,6,13,16-19,24,39}$

The need for a more sensitive, specific and real-time test/ biomarker of $\mathrm{AKI}$ is because $\mathrm{SCr}$ levels and urine production are not time-sensitive markers of AKI, as they may take up to 48 hours to change after an insult has occurred. ${ }^{1,3,10,13,16,19,24}$ When trying to predict the onset of a disease, the use of a retrospective marker is not logical, especially one that can be as delayed as the rise in $\mathrm{SCr}$. The change in $\mathrm{SCr}$ used in the KDIGO criteria to detect the occurrence of $\mathrm{AKI}$, cannot be used to predict the occurrence of AKI before the insult occurs. ${ }^{3}$

$\mathrm{SCr}$ alone may not assist with the evaluation of potentially damaged or at-risk renal cellular tissue. ${ }^{4,7-12}$ Its use, therefore, is significant in established disease, and cannot be used to preempt or anticipate the onset of AKI. There is therefore a need for methods to predict or preempt AKI, to ensure that the KDIGO preventative and supportive managements strategies can be implemented early. 


\section{Novel biomarkers of AKI}

Novel biomarkers for diagnosis of AKI have been the focus of ongoing interest. ${ }^{6-9,11,12,40}$ Biomarkers that have provoked discussion are Cystatin $C$, neutrophil gelatinase-associated lipocalin (NGAL), tissue inhibitor of metalloproteinase 2 (TIMP2), insulin-like growth factor binding protein 7 (IGFBP7), kidney injury molecule 1 (KIM-1), interleukin 18 (IL-18) and liver fatty acid-binding protein (L-FABP). ${ }^{6-9,11,12,25,40}$ Biomarkers that have gained the most attention as potentially useful from current practice are NGAL, TIMP-2 and IGFBP7. ${ }^{-9,911,12,40}$

NGAL is a marker produced by the renal tubules and released into the bloodstream after an insult has occurred, and increased levels can be detected within two hours of the injury. ${ }^{6,7} \mathrm{NGAL}$ is a component of the innate immune system but has multiple functions in the human body. ${ }^{6,7}$ It is bacteriostatic, is involved in cellular pathway signalling and is embryologically important for the development of renal tissue. ${ }^{6,7}$ It is upregulated shortly after an insult to the kidney has occurred, and is thought to appear when structural damage has occurred to the renal tubular cells, but prior to established dysfunction. ${ }^{6,7}$ It is, therefore, present in urine and blood tests shortly after injury has occurred, however it is also produced by injured epithelial cells of liver, colon and lung. 6,7

Its use for CSA AKI in adults appears to have promising results, however when tested in the paediatric population it appeared disappointing. ${ }^{7}$ Given that it is a biomarker of cellular stress or injury, it is tested when AKI is suspected, and therefore not as surveillance preoperatively. ${ }^{6,7,12}$

TIMP-2 and IGFBP7 are two biomarkers that are indicators of cell cycle arrest.8,9,11,12,40 They are produced when the cell enters but fails to exit cell cycling, and their production results in $G_{1}$ cell arrest, a known consequence of AKI, which results in inhibition of angiogenesis and endothelial cell proliferation. $8,9,11,12,40$ The combination of these two biomarkers was shown to detect an increase in the risk of AKI seven-fold compared to NGAL $(p<0.002) .8,11,12,40$ A laboratory test kit, the NephroCheck ${ }^{\circledR}$ (Figure 2), which has been approved for use by the FDA, makes use of this combination (TIMP-2 and IGFBP7). ${ }^{8,12}$ It has been used to identify patients at risk of developing AKI following cardiac surgery, which could assist with the timely institution of preventative

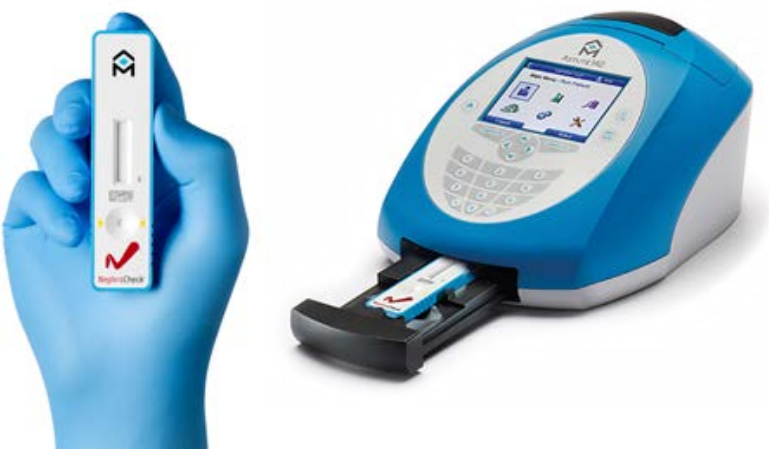

Figure 2: The NephroCheck ${ }^{\circledast}$, an FDA-approved laboratory test. It is used to measure urinary levels of serum biomarkers present in patients who have, or develop, $\mathrm{AKI}^{41,42}$ measures. Currently, the largest obstacle to its implementation in routine clinical practice is cost and availability.

\section{Novel use of vascular ultrasound in the diagnosis of AKI}

The use of ultrasound has gained popularity due to its inherent properties. ${ }^{15,25-27,29,30,43-46}$ It is non-invasive, portable, well-tolerated by patients and produces real-time results. ${ }^{46-48}$ Specifically, Duplex Doppler, a combination of Colour Doppler (CD) and brightness mode ultrasonography, which gives descriptive information on flow patterns using hue and colour, has recently shown promising results as a novel technique to assist with early identification and prognostication of AKI. ${ }^{26-32,36,43-46,49-54}$ It has been used successfully to define venous and arterial renal parameters in the perioperative period, such as the renal resistive index, renal venous flow patterns, portal pulsatility and portal venous flow..$^{15,26,28-30,43-45,49,53,55}$ These parameters are described individually below.

\section{Arterial profile: the renal resistive index}

The renal arterial resistive index (RI), as defined by Pourcelot's formula ${ }^{53,56,57}$ has recently been used as a predictor of ensuing and persistent AKI. $27,28,32,45,49,53$ Resistive index is a measure of pulsatile blood flow that reflects the resistance to blood flow caused by the microvascular bed distal to the site of measurement. $15,24,25,27,28,44,45,49,53$ The formula used to calculate resistive index is as follows: $53,56,57$

$$
\mathrm{RI}=\frac{\mathrm{v} \text { (systole })-\mathrm{v} \text { (diastole) }}{\mathrm{v}(\text { systole })}
$$

where $v$ describes the velocity of blood flow. It is calculated using the intralobar/arcuate artery, where an average is taken using the cranial, central and caudal arteries..$^{27,28,43,49,53}$ It can be performed pre- and postoperatively to assist with clinical judgement and decision making. It is performed through the translumbar ultrasound windows with the patient lying supine, using a curvilinear probe (Figures 3 and 4). The probe is aligned to the eleventh and twelfth ribs on each side, along the anterior axillary line. ${ }^{46,47,55} \mathrm{~A}$ sagittal view of the kidneys can be obtained

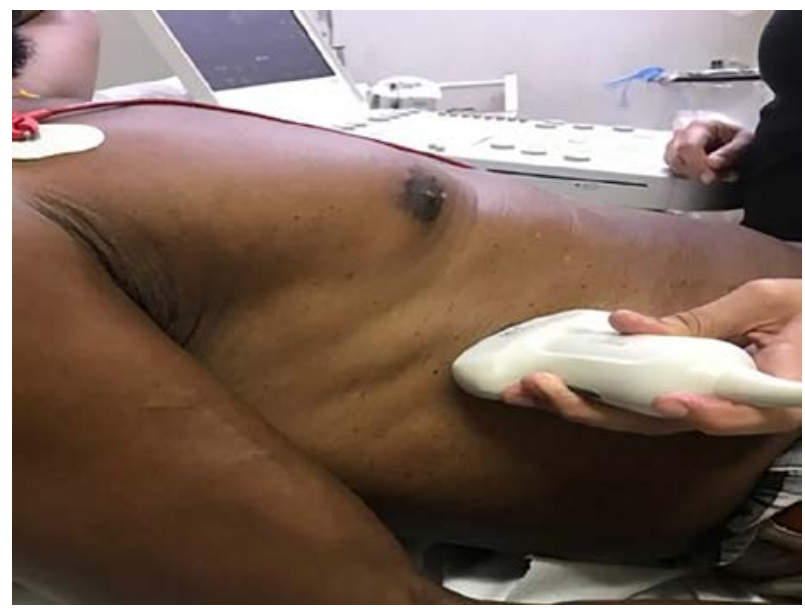

Figure 3: Illustration of probe position for renal vascular image acquisition (consent obtained from patient) 

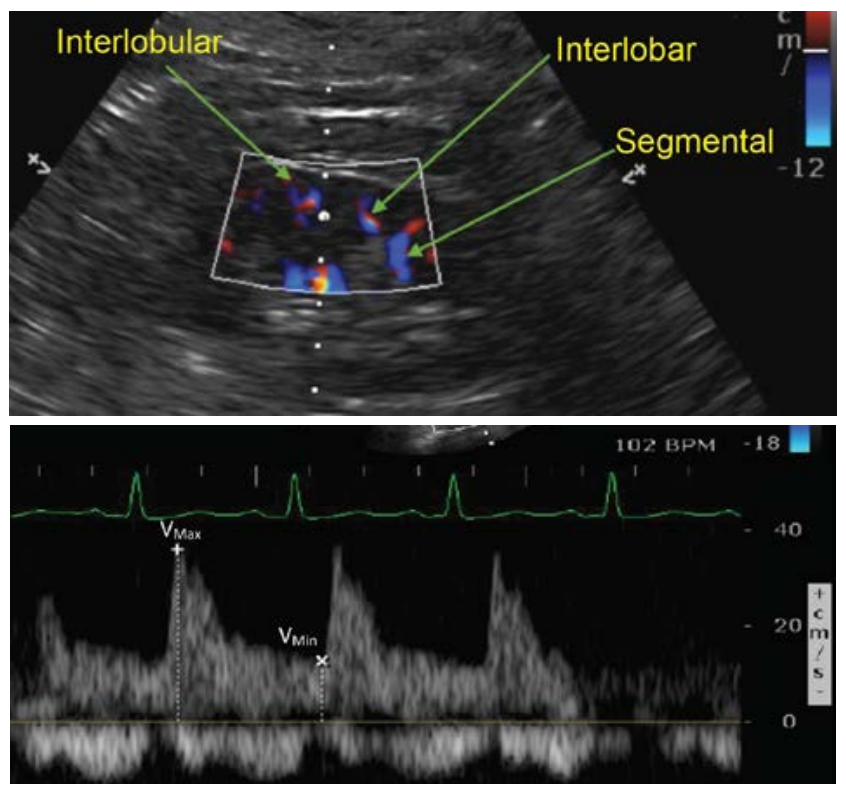

Figure 4: Colour Doppler of the right kidney and its vessels (top) and normal Doppler of interlobar artery with tracing depicting below (bottom) $)^{55}$

by rotating the probe from $0^{\circ}$ to $45^{\circ} .46,47,55$ Using $C D$, vessels can be delineated and pulsed wave doppler (PWD) applied, the RI can be calculated using the arterial waveform pattern. ${ }^{15,26,47,54,55}$ It can also be performed intraoperatively, with the use of a transoesophageal (TEE) probe as described by Bandyopadhyay et al. ${ }^{58}$ through the transgastric view using the corkscrew method. The method is only described for the left kidney as images of the right kidney are more difficult to obtain due to its anatomical position (Figure 5).

The classification of flow patterns in relation to $\mathrm{RI}$ is tabulated (Table II). Using a cut-off value of $>0.70$, the RI has been independently used to risk stratify morbidity, namely the development of sepsis, prolonged ventilation and the progression of heart failure..$^{28,44}$

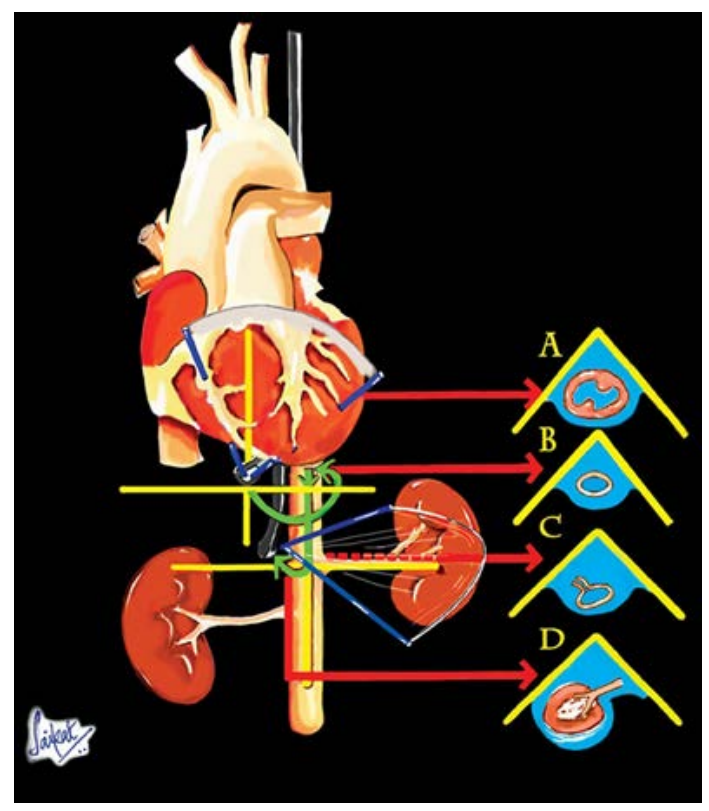

Figure 5: Illustration of the Corkscrew Technique using TEE to visualise renal vessels ${ }^{58}$
Table II: Classification of resistive index $26,29,30,57$

\begin{tabular}{ll}
\hline Resistive index (value) & Description of flow \\
\hline 0 & Continuous \\
1 & Systolic present, diastolic absent \\
$>1$ & Reversed diastolic flow \\
\hline
\end{tabular}

In a systematic review of 154 studies over 28 years by Ninet et al., ${ }^{53}$ Doppler-based RI and prediction of reversibility of renal dysfunction were assessed. They found that RI could be used as a predictor of persistent AKI. $26,30,55$ Use of this modality in cardiac surgery is still new.

Bedside RI allows estimation of the renal vascular resistance, and a value $>0.70$ has been found to be associated with an increased likelihood of major postoperative adverse outcomes. ${ }^{44}$ RI can be influenced by parenchymal and vascular abnormalities such as: variations in vascular compliance; heart rate and rhythm; increased intra-abdominal pressure; and ureteric obstruction. . $^{17,28,49}$ More studies in this area are necessary.

\section{Venous profile: renal, portal and hepatic flow patterns}

In the venous system, Duplex Doppler and waveform analysis have been used to identify surrogates of renal venous congestion. ${ }^{26,30-32,36,55}$ Central venous pressure (CVP) is a component of right atrial pressure, and inferior vena cava (IVC) pressures are a component of CVP. ${ }^{31,36,50-52}$ An elevated CVP can, therefore, be indicative of venous congestion provided supradiaphragmatic causes of obstruction such as pneumothorax, cardiac tamponade and excessive positive end expiratory pressure are ruled out, or it can be a function of diastolic dysfunction. ${ }^{36,50-52}$

Given the intimate relationship between the cardiac and renal axes, Doppler assessment of the cardiac system must be considered when investigating the renal system. ${ }^{50,51,59-61}$ Systolic and diastolic function of the heart can be calculated using Doppler, and can be used to stratify patients based on their echocardiographic features, as described by Choi et al. ${ }^{61}$ Patients with more severe cardiac dysfunction (systolic or diastolic) had an increased risk of developing $\mathrm{AKI}$ as well as long term renal impairment. ${ }^{61}$

Assessment of diastolic function can assist in differentiating between true diastolic dysfunction and volume overload, which results in elevated pressures in the abdominal venous system. . $^{52,61,62} \mathrm{~A}$ high CVP, secondary to venous congestion, has been shown to be associated with increased postoperative mortality. 31,33-36,38,39,63 With these increased venous pressures, the IVC becomes non-compliant and right atrial pressures are transmitted throughout the cardiac cycle into the abdominal

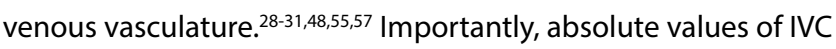
measurements do not accurately predict CVP measurements, but rather the IVC collapsibility and inspiratory-expiratory variations, which can discriminate between low/normal CVP and high CVP readings. ${ }^{26,30,31,36}$ 


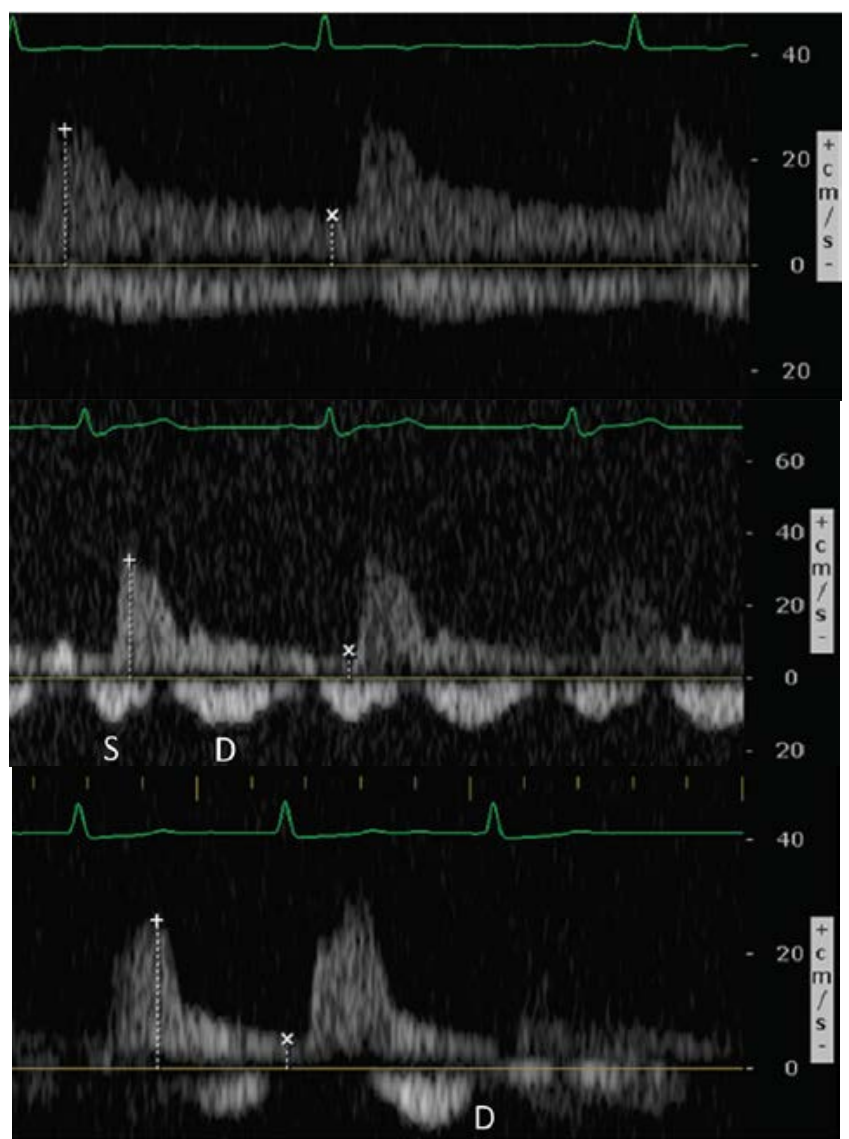

Figure 6: Intrarenal venous flow patterns of the right interlobar veins using colour Doppler

Normal wave form pattern (top) showing continuous flow throughout the cardiac cycle vs discontinuous biphasic venous flow with systolic and diastolic component (middle) vs discontinuous wave form pattern (bottom) with flow only present during diastole ${ }^{30}$

Under physiological conditions, renal venous flow is uninterrupted. In the face of venous congestion, it becomes biphasic, then monophasic, and finally completely discontinuous with severe congestion. ${ }^{26}$ Intrarenal venous flow (IRVF) patterns (Figure 6) have been found to be strongly correlated with adverse clinical outcomes, and to independently predict increased risk of perioperative AKI and mortality. ${ }^{26,30,55}$ The venous flow patterns are categorised based on the data captured from analysing the arcuate/intralobar veins cranially, centrally and caudally. ${ }^{26,30,47,55}$
The ideal positioning is with the patient supine, or in the left/ right lateral decubitus positions, with the probe aligned with the eleventh and twelfth ribs, in the anterior axillary line. ${ }^{30,36,43,46,47}$ These measurements can also be obtained preand postoperatively as comparatives so as to detect the change in ultrasonographic data. These parameters can be obtained through standard translumbar renal ultrasound or TEE, with the use of PWD to categorise the flow patterns..$^{30,47,48}$

Portal venous flow (Figure 7) tends to be protected from backward venous pressure due to its anatomy, therefore, when differences between systolic and diastolic velocities exist, it is indicative of abnormal flow. ${ }^{29,30,36,55}$ With the patient in the supine position, or the left/right lateral decubitus position, the probe in the eight to eleventh intercostal spaces, midaxillary line, $C D$ can be used to identify the portal vein coronally, and PWD to determine the maximal systolic and diastolic flow velocities. ${ }^{36,47,48,55}$

When portal flow pulsatility [(systolic velocity - diastolic velocity) / systolic velocity] is $>50 \%$ it is considered a marker of venous congestion. ${ }^{29,30,36,55}$ It has been found to be an independent factor in predicting CSA AKI, together with intrarenal venous flow patterns. ${ }^{29,30,55}$ When evaluated perioperatively, it could provide information on the presence of congestion, if compared to preoperative values. ${ }^{29,30,32}$ When used in conjunction with IRVF patterns, it assists in differentiating between supradiaphragmatic causes of venous obstruction, portal hypertension and true venous congestion, which can prove invaluable in the real-time setting of intraoperative decision making. ${ }^{15,29,30,32,55}$

Hepatic venous flow pattern (Figure 8), can also assist with the diagnosis and identification of venous congestion. ${ }^{29,30,36,55}$ With the patient in the supine position, the probe aligned from the seventh to tenth intercostal space, lateral to the midclavicular line, the hepatic vein can be identified using CD, and PWD used to categorise the flow pattern. ${ }^{29,30,36,47,55}$ Under physiological conditions, the hepatic vein has a systolic:diastolic ratio of $>1$, which is reversed when venous congestion is present. ${ }^{29,30,55}$ When flow is significantly affected, the diastolic component of the cardiac cycle exceeds the systolic component, with
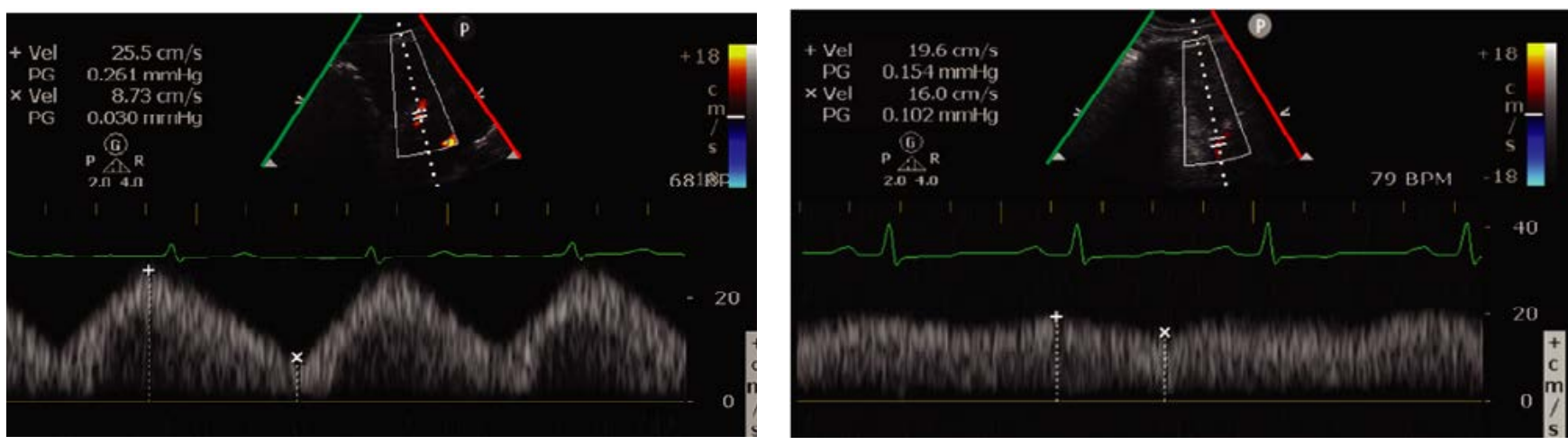

Figure 7: Duplex Doppler of portal venous waveform patterns and pulsatility fraction ${ }^{30}$

Normal portal flow (right) showing minimal differences between Vmax and Vmin, with lower pulsatility fraction vs abnormal variations (left) of flow velocities during the cardiac cycle (values of $>50 \%$ considered abnormal) where significant changes noted between Vmax and Vmin, resulting in higher pulsatility fraction (pulsatility fraction $18.4 \%$ vs $66 \%)$ 


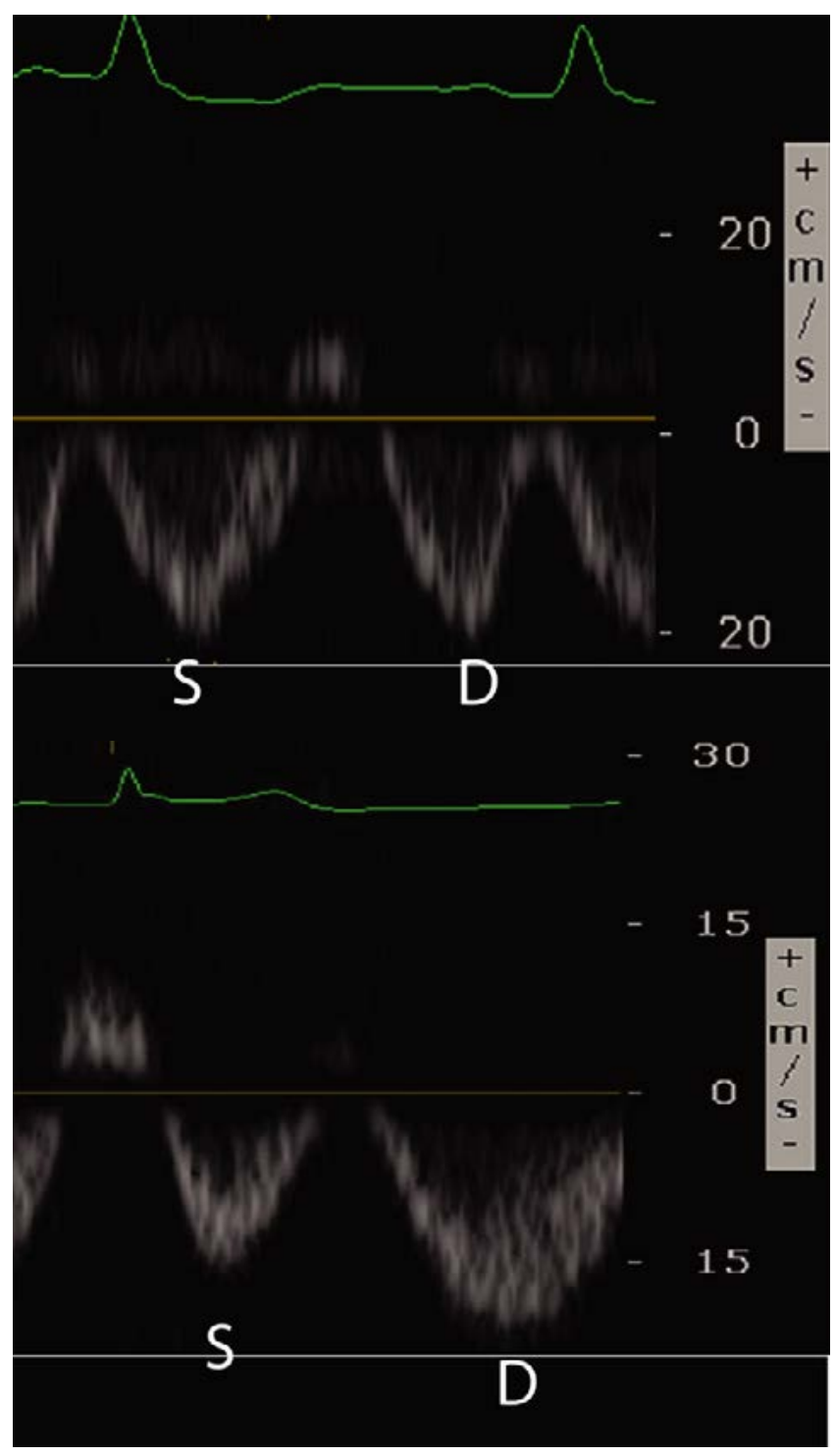

Figure 8. Duplex Doppler of hepatic venous waveform patterns ${ }^{30}$

Normal hepatic venous waveform (top) with systolic (S) component $\geq$ diastolic component (D) vs abnormal (bottom) with systolic component $(\mathrm{S})<(\mathrm{D})$.

attenuation of the systolic flow and eventually reversal of normal atrial flow. ${ }^{29,30,36,55}$

These perioperative ultrasonographic parameters, in varying combinations have been reviewed and shown interesting results, given the benefits of real-time changes and clear demarcations of indices, as outlined by the various formulae. The use of these ultrasonographic features to diagnose and predict ensuing AKI has recently been reviewed by Beaubien-Souligny et al..$^{55}$ in cardiac surgical patients and have shown that the perioperative comparative change within an individual, with the use of sound clinical judgement and understanding of the interpretation of ultrasonographic detail, can be invaluable.

\section{Management of AKI}

The fundamental principle underlying the treatment of AKI is to treat the cause and, therefore, the importance of identifying and risk stratifying patients according to their predisposing and precipitating factors is imperative. ${ }^{2-5,13,16,64}$ Important directives to achieve in minimising CSA AKI are to prevent or limit ischaemia, decrease inflammation, modify amenable risk factors, address nutritional status and manage fluid status appropriately. ${ }^{2-5,13,16,64}$ The goal of early initiation of therapy is to limit the severity of the complications; it has been found, however, that initiation of RRT early in the treatment plan results in better outcomes for both CSA AKI and non-CSA AKI. ${ }^{1,14,33}$

The notion of fluid therapy is central to the prevention and treatment of AKI, yet, there is no standardised fluid management strategy. ${ }^{3,33,34}$ Positive fluid balance in critically ill patients results in worse outcomes, such as prolonged hospital stay, increased risk of respiratory failure requiring ventilation, and risk of longterm progression to renal dysfunction. ${ }^{33-35,63}$ Fluid overload in patients with AKI has been shown to be an independent risk factor for mortality, regardless of the need for RRT, and cardiac surgery complicates the considerations, as it poses multiple risk factors that too can damage the endothelial glycocalyx, leading to "leaky" capillaries and rapid accumulation of fluid in the interstitium. ${ }^{5,33-36,63}$

The clinical conundrum, therefore, arises with patients who develop CSA AKI, and yet are fluid-replete, as nutritional requirements will still demand an intake of approximately 1 litre per day, which cannot be counteracted by insensible losses alone, directing therapy to initiate RRT earlier, so as to avoid fluid overload. ${ }^{2-4,22,33-36,63}$ The lack of unanimity regarding specific fluid management strategies for patients with CSA AKI remains problematic.

\section{Conclusion}

Novel techniques to diagnose AKI timeously are clinically relevant and important. Duplex Doppler appears to be showing promising results in $\mathrm{RI}$, IRVF patterns, portal and hepatic venous flow, and cardiac profiles. Further investigations into these parameters, and possible use of biomarkers to correlate with the degree of AKI could prove to assist with earlier detection of CSA AKI.

\section{Acknowledgements}

The authors would like to thank the American Journal of Cardiology and the Journal of the American Heart Association, for permission to use the images from published articles, as well as the KDIGO group, for use of the table from published guidelines. The authors would also like to thank Dr Ronco, Dr Bandyopadhyay and Dr Beaubien-Souligny for permission to use images from previously published articles.

\section{Conflict of interest}

The authors declare no conflict of interest.

\section{Funding source}

None. 


\section{ORCID}

\section{G Pettey iD https://orcid.org/0000-0001-8983-0825P P Motshabi iD https://orcid.org/0000-0001-9990-6336}

\section{References}

1. O'Neal JB, Shaw AD, Billings FT. Acute kidney injury following cardiac surgery: current understanding and future directions. Crit Care [Internet]. 2016 [cited 2018 Nov 13];20. Available from: https://www.ncbi.n/m.nih.gov/pmc/articles/ PMC4931708/.https://doi.org/10.1186/s13054-016-1352-z.

2. Bellomo R, Kellum JA, Ronco C. Acute kidney injury. Lancet. 2012 Aug 25;380(9843):756-66. https://doi.org/10.1016/S0140-6736(11)61454-2.

3. Kellum JA, Lameire N. Official journal of the international society of nephrology KDIGO Clinical practice guidleines for acute kidney injury. Official Journal of the International Society of Nephrology. 2012;2(1):141.

4. Zarbock A, Kellum JA. Acute kidney injury in cardiac Surgery. In: Critical care nephrology [Internet]. 3rd ed. Philadelphia, PA: Elsevier; 2019. p. 250-254.e2. Available from: https://www.clinicalkey.com/\#!/content/book/3-s2.0-B97803234 4942700042X?scrollTo=\%23hl0000135.

5. Miller R, Young W, Eriksson L, Fleisher L, Wiener-Kronish J, Cohen N. Miller's Anesthesia, 2-Volume Set - 8th ed. In: Miller's Anaesthesia [Internet]. 8th ed. Saunders; 2014 [cited 2018 Nov 22]. p. 547-67, 576-8, 2041-7, 2080-6. Available from: https://www.elsevier.com/books/millers-anesthesia-2-volume-set/ miller/978-0-7020-5283-5.

6. Bolignano D, Donato V, Coppolino G, et al. Neutrophil gelatinase-associated lipocalin (NGAL) as a marker of kidney damage. Am J Kidney Dis. 2008 Sep;52(3):595-605. https://doi.org/10.1053/j.ajkd.2008.01.020.

7. Devarajan $P$. Neutrophil gelatinase-associated lipocalin: a promising biomarker for human acute kidney injury. Biomark Med. 2010 Apr;4(2):265-80. https://doi. org/10.2217/bmm.10.12.

8. Gunnerson KJ, Shaw AD, Chawla LS, et al. TIMP2.IGFBP7 biomarker panel accurately predicts acute kidney injury in high-risk surgical patients. J Trauma Acute Care Surg. 2016 Feb;80(2):243-9. https://doi.org/10.1097/ TA.0000000000000912

9. Vijayan A, Faubel S, Askenazi DJ, et al. Clinical use of the urine biomarker [TIMP-2] $\times$ [IGFBP7] for acute kidney injury risk assessment. Am J Kidney Dis. 2016 Jul;68(1):19-28. https://doi.org/10.1053/j.ajkd.2015.12.033.

10. Englberger $L$, Suri RM, Li Z, et al. Validation of clinical scores predicting severe acute kidney injury after cardiac surgery. Am J Kidney Dis. 2010;(56):623-31. https://doi.org/10.1053/j.ajkd.2010.04.017.

11. Kashani K, Al-Khafaji A, Ardiles T, et al. Discovery and validation of cell cycle arrest biomarkers in human acute kidney injury. Crit Care. 2013 Feb 6;17(1):R25. https://doi.org/10.1186/cc12503.

12. Kellum JA, Chawla LS. Cell-cycle arrest and acute kidney injury: the light and the dark sides. Nephrol Dial Transpl. 2016 Jan;(31):16-22. https://doi.org/10.1093/ ndt/gfv130.

13. Mariscalco G, Lorusso R, Dominici C, Renzulli A, Sala A. Acute kidney injury: a relevant complication after cardiac surgery. Ann Thorac Surg. 2011 Oct;92(4):1539-47. https://doi.org/10.1016/j.athoracsur.2011.04.123.

14. Liu Y, Davari-Farid S, Arora P, Porhomayon J, Nader ND. Early versus late initiation of renal replacement therapy in critically ill patients with acute kidney injury after cardiac surgery: a systematic review and meta-analysis. J Cardiothorac Vasc Anesth. 2014 Jun;28(3):557-63. https://doi.org/10.1053/j.jvca.2013.12.030.

15. Bossard G, Bourgoin P, Corbeau JJ, Huntzinger J, Beydon L. Early detection of postoperative acute kidney injury by Doppler renal resistive index in cardiac surgery with cardiopulmonary bypass. Br J Anaesth. 2011 Dec 1;107(6):891-8. https://doi.org/10.1093/bja/aer289.

16. Ichai C, Vinsonneau C, Souweine B, et al. Acute kidney injury in the perioperative period and in intensive care units (excluding renal replacement therapies). Ann Intensive Care. 2016 Dec;6(1):48. https://doi.org/10.1186/s13613-016-0145-5.

17. Schneider AG, Goodwin MD, Bellomo R. Measurement of kidney perfusion in critically ill patients. Crit Care. 2013;17(2):220. https://doi.org/10.1186/cc12529.

18. Traynor J, Mactier R, Geddes CC, Fox JG. How to measure renal function in clinical practice. BMJ. 2006 Oct 7;333(7571):733-7. https://doi.org/10.1136/ bmj.38975.390370.7C.

19. Ryckwaert F, Boccara G, Frappier J-M, Colson PH. Incidence, risk factors, and prognosis of a moderate increase in plasma creatinine early after cardiac surgery*. J Crit Care Med. 2002 Jul;30(7):1495-8. https://doi. org/10.1097/00003246-200207000-00016.

20. D'Agostino RS, Jacobs JP, Badhwar V, Fernandez FG, Paone G, Wormuth DW, et al. The Society of Thoracic Surgeons Adult Cardiac Surgery Database: 2018 Update on outcomes and quality. Ann Thorac Surg. 2018 Jan 1;105(1):15-23. https://doi. org/10.1016/j.athoracsur.2017.10.035.

21. Thakar CV, Arrigain S, Worley S, Yared J-P, Paganini EP. A clinical score to predict acute renal failure after cardiac surgery. J Am Soc Nephrol. 2005 Dec 1;16(1):1628. https://doi.org/10.1681/ASN.2004040331.

22. Birnie K, Verheyden V, Pagano D, et al. Predictive models for kidney disease: improving global outcomes (KDIGO) defined acute kidney injury in UK cardiac surgery. Crit Care. 2014 Nov 20;18(6):606. https://doi.org/10.1186/ s13054-014-0606-X.
23. Machado MN, Nakazone MA, Maia LN. Acute kidney injury based on KDIGO (Kidney Disease Improving Global Outcomes) criteria in patients with elevated baseline serum creatinine undergoing cardiac surgery. Rev Bras Cir Cardiovasc. 2014 Sep;29(3):299-307. https://doi.org/10.5935/1678-9741.20140049.

24. Schnell D, Camous L, Guyomarc'h S, et al. Renal perfusion assessment by renal doppler during fluid challenge in sepsis: J Crit Care Med. 2013 May;41(5):121420. https://doi.org/10.1097/CCM.0b013e31827c0a36.

25. Schnell $D$, Deruddre $S$, Harrois $A$, et al. Renal resistive index better predicts the occurrence of acute kidney injury than cystatin C. Shock. 2012 Dec;38(6):592-7. https://doi.org/10.1097/SHK.0b013e318271a39c.

26. lida $N$, Seo $Y$, Sai $S$, et al. Clinical implications of intrarenal hemodynamic evaluation by doppler ultrasonography in heart failure. JACC Heart Fail. 2016;4(8):674-82. https://doi.org/10.1016/j.jchf.2016.03.016.

27. Lerolle $N$, Guérot $E$, Faisy $C$, et al. Renal failure in septic shock: predictive value of Doppler-based renal arterial resistive index. Intensive Care Med. 2006 Aug 29;(32):1553-9. https://doi.org/10.1007/s00134-006-0360-x.

28. Darmon $M$, Schortgen $F$, Vargas $F$, et al. Diagnostic accuracy of Dopple renal resistive index for reversibility of acute kidney injury in critically ill patients. Intensive Care Med. 2011 Jan 1;37(1):68-76. https://doi.org/10.1007/ s00134-010-2050-y.

29. Beaubien-Souligny W, Eljaiek R, Fortier A, et al. The association between pulsatile portal flow and acute kidney injury after cardiac surgery: a retrospective cohort study. J Cardiothorac Vasc Anesth. 2018;32(4):1780-7. https://doi.org/10.1053/j. jvca.2017.11.030

30. Beaubien-Souligny W, Benkreira A, Robillard P, et al. Alterations in portal vein flow and intrarenal venous flow are associated with acute kidney injury after cardiac surgery: a prospective observational cohort study. J Am Heart Assoc. 2018 Oct 2;7(19):e009961. https://doi.org/10.1161/JAHA.118.009961.

31. Ilyas A, Ishtiaq W, Assad S, et al. Correlation of IVC diameter and collapsibility index with central venous pressure in the assessment of intravascular volume in critically ill patients. Cureus 9(2): e1025. https://doi.org/10.7759/cureus.1025.

32. Mullens W, Abrahams Z, Francis GS, et al. Importance of venous congestion for worsening of renal function in advanced decompensated heart failure. J Am Coll Cardiol. 2009 Feb 17;53(7):589-96. https://doi.org/10.1016/j.jacc.2008.05.068.

33. Payen D, De Pont AC, Sakr Y, et al. A positive fluid balance is associated with a worse outcome in patients with acute renal failure. Crit Care. 2008:12(3):R74 https://doi.org/10.1186/cc6916.

34. Bouchard J, Soroko SB, Chertow GM, et al. Fluid accumulation, survival and recovery of kidney function in critically ill patients with acute kidney injury. Kidney Int. 2009 Aug 2;76(4):422-7. https://doi.org/10.1038/ki.2009.159.

35. O'Connor ME, Prowle JR. Fluid overload. Crit Care Cli. 2015;31(4):803-21. https:// doi.org/10.1016/j.ccc.2015.06.013.

36. Beaubien-Souligny W, Bouchard J, Desjardins G, et al. Extracardiac signs of fluid overload in the critically ill cardiac patient: a focused evaluation using bedside ultrasound. Can J Cardiol. 2017;33(1):88-100. https://doi.org/10.1016/j. cjca.2016.08.012.

37. Ljungman $\mathrm{S}$, Laragh $\mathrm{JH}$, Cody RJ. Role of the kidney in congestive heart failure Relationship of cardiac index to kidney function. Drugs. 1990;39 Suppl 4:10-21; discussion 22-4. https://doi.org/10.2165/00003495-199000394-00004.

38. Winton FR. The influence of venous pressure on the isolated mammalian kidney. J Physiol. 1931 Jun 6;72(1):49-61. https://doi.org/10.1113/jphysiol.1931. sp002761.

39. Bastin AJ, Ostermann M, Slack AJ, et al TW. Acute kidney injury after cardiac surgery according to Risk/Injury/Failure/Loss/End-stage, Acute Kidney Injury Network, and Kidney Disease: Improving Global Outcomes classifications. J Crit Care. 2013 Aug 1;28(4):389-96. https://doi.org/10.1016/j.jcrc.2012.12.008.

40. Bihorac $A$, Chawla $L S$, Shaw $A D$, et al. Validation of cell-cycle arrest biomarkers for acute kidney injury using clinical adjudication. Am J Respir Crit Care Med. 2014 Apr 15;189(8):932-9. https://doi.org/10.1164/rccm.201401-00770C.

41. AKI Risk Assessment Test System [Internet]. The NEPHROCHECK ${ }^{\circledast}$ Test. [cited 2019 Nov 18]. Available from: https://www.nephrocheck.com/aki-risk-assessment/.

42. NEPHROCHECK ${ }^{\circledR}$ [Internet]. bioMérieux. [cited 2019 Nov 18]. Available from: https://www.biomerieux-usa.com/clinical/nephrocheck.

43. Cansu A, Kupeli A, Kul S, et al. Evaluation of the relationship between renal function and renal volume-vascular indices using 3D power Doppler ultrasound. Eur J Radiol. 2014 Jul;83(7):1080-5. https://doi.org/10.1016/j.ejrad.2014.04.007.

44. Giustiniano $E$, Meco $M$, Morenghi $E$, et al. May renal resistive index be an early predictive tool of postoperative complications in major surgery? Preliminary results [Internet]. www.hindawi.com/journals/bmri.2014 [cited 2018 Dec 10]. https://doi.org/10.1155/2014/917985.

45. Dewitte A, Coquin J, Meyssignac B, et al. Doppler resistive index to reflect regulation of renal vascular tone during sepsis and acute kidney injury. Crit Care. 2012 Sep 12;16(5):R165. https://doi.org/10.1186/cc11517.

46. Gosmanova EO, Wu S, O'Neill WC. Application of ultrasound in nephrology practice. Adv Chronic Kidney Dis. 2009 Sep;16(5):396-404. https://doi. org/10.1053/j.ackd.2009.07.001.

47. Cheung ME, Firstenberg MS. Duplex ultrasound. In: StatPearls [Internet]. Treasure Island (FL): StatPearls Publishing; 2018 [cited 2018 Dec 10]. Available from: http://www.ncbi.nlm.nih.gov/books/NBK459266/.

48. Hagen-Ansert, Sandra L. Foundations of clinical sonography. In: Textbook of Diagnostic Sonography [Internet]. 8th ed. Elsevier, Inc; 2018 [cited 2018 
Nov 21]. p. 1-23. Available from: https://www.clinicalkey.com/\#!/content/ book/3-s2.0-B9780323353755000108?scrollTo=\%23hl0001010

49. Ciccone $M M$, lacoviello $M$, Gesualdo $L$, et al. The renal arterial resistance index: a marker of renal function with an independent and incremental role in predicting heart failure progression. Eur J Heart Fail. 2014 Feb 1;16(2):210-6. https://doi. org/10.1002/ejhf.34.

50. Little WC, Oh JK. Echocardiographic evaluation of diastolic function can be used to guide clinical care. Circulation. 2009 Sep;120(9):802-9. https://doi. org/10.1161/CIRCULATIONAHA.109.869602.

51. Hu K, Liu D, Herrmann $\mathrm{S}$, et al. Clinical implication of mitral annular plane systolic excursion for patients with cardiovascular disease. Eur Heart J Cardiovasc Imaging. 2013 Mar;14(3):205-12. https://doi.org/10.1093/ehjci/jes240.

52. Thomas JD, Popović ZB. Assessment of left ventricular function by cardiac ultrasound. J Am Coll Cardiol. 2006 Nov 21;48(10):2012-25. https://doi. org/10.1016/j.jacc.2006.06.071.

53. Ninet $S$, Schnell D, Dewitte $A$, et al. Doppler-based renal resistive index for prediction of renal dysfunction reversibility: A systematic review and meta-analysis. Crit Care. 2015 Jun;30(3):629-35. https://doi.org/10.1016/j. jcrc.2015.02.008

54. Uppal T, Mogra R. RBC motion and the basis of ultrasound Doppler instrumentation. Australas J Ultrasound Med. 2010 Feb;13(1):32-4. https://doi. org/10.1002/j.2205-0140.2010.tb00216.x

55. Beaubien-Souligny W, Denault A, Robillard P, Desjardins G. The role of point-ofcare ultrasound monitoring in cardiac surgical patients with acute kidney Injury. J Cardiothorac Vasc Anesth. 2019 Oct 1;33(10):2781-96. https://doi.org/10.1053/j. jvca.2018.11.002.

56. O'Rourke MF, Nichols WW. McDonald's Blood flow in arteries: Theoretical, experimental and clinical principles. In: CRC Press [Internet]. 3rd ed. Philadelphia, PA: Elsevier Publisher; 1990 [cited 2018 Nov 16]. p. 11. Available from: https://www.crcpress.com/
McDonalds-Blood-Flow-in-Arteries-Theoretical-Experimental-and-Clinical/ Vlachopoulos-ORourke-Nichols/p/book/9780340985014.

57. Bude RO, Rubin JM. Relationship between the resistive index and vascular compliance and resistance. Radiology. 1999 May;211(2):411-7. https://doi. org/10.1148/radiology.211.2.r99ma48411.

58. Bandyopadhyay S, Kumar Das R, Paul A, Sundar Bhunia K, Roy D. A Transesophageal echocardiography technique to locate the kidney and monitor renal perfusion. Anesth Analg. 2013 Mar;116(3):549-54. https://doi.org/10.1213/ ANE.0b013e31827ab3b1.

59. Soman S, Chitturi C. Cardiorenal syndrome. In: Ferri's Clinical Advisor 2019 [Internet]. Philadelphia, PA: Elsevier; 2019 [cited 2018 Nov 14]. p. 284 E2-4. Available from: https://www.clinicalkey.com/\#!/content/book/3-s2.0-B97803235 30422001528?scrollTo=\%23hl0000202.

60. Ronco C, Haapio M, House AA, Anavekar N, Bellomo R. Cardiorenal Syndrome. JACC. 2008 Nov;52(19):1527-39. https://doi.org/10.1016/j.jacc.2008.07.051.

61. Choi JS, Baek SH, Chin HJ, et al. Systolic and diastolic dysfunction affects kidney outcomes in hospitalized patients. BMC Nephrol. 2018 Oct;19: 292. https://doi. org/10.1186/s12882-018-1103-2.

62. Sohn D-W, Chai I-H, Lee D-J, et al. Assessment of mitral annulus velocity by Doppler tissue imaging in the evaluation of left ventricular diastolic function. J Am Coll Cardiol. 1997 Aug;30(2):474-80. https://doi.org/10.1016/ S0735-1097(97)88335-0.

63. Brandstrup B, Tønnesen H, Beier-Holgersen R, et al. Effects of intravenous fluid restriction on postoperative complications: comparison of two perioperative fluid regimens: a randomized assessor-blinded multicenter trial. Ann Surg. 2003 Nov;238(5):641-8. https://doi.org/10.1097/01.sla.0000094387.50865.23.

64. Thakar CV, Liangos O, Yared JP, et al. ARF after open-heart surgery: Influence of gender and race. Am J Kidney Dis. 2003;41(4):742-51. https://doi.org/10.1016/ S0272-6386(03)00021-0. 